\title{
Vital Signs Planned Time Point Number
}

National Cancer Institute

\section{Source}

National Cancer Institute. Vital Signs Planned Time Point Number. NCI Thesaurus. Code C83467.

The numerical identifier of a vital signs point in time. 